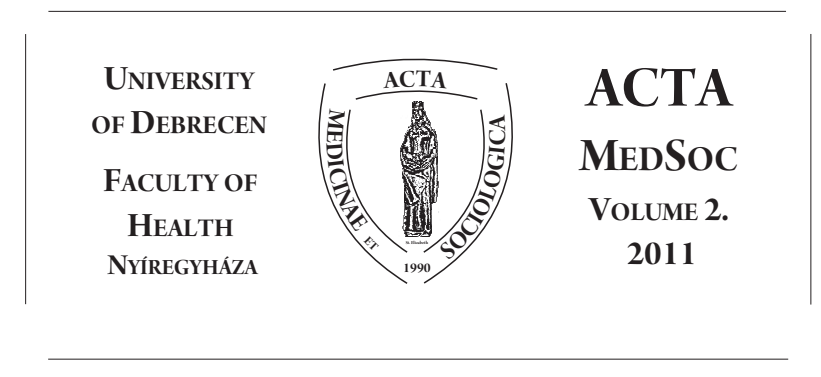

\title{
From sociometry to network diary Measuring personal networks
}

\author{
Éva Huszti \\ University of Debrecen, Faculty of Health
}

\begin{abstract}
There are many studies which deal with personal networks. We have known many methods to measure ego-centred networks. In this study I would like to introduce an alternative data collecting method to measure personal networks which is network diary. Firstly I would like to give a brief summary of methods which were used during data collection in the field of ego-centred networks. Then I would like to show the new method and some results of it. Finally I would try to sum up the advantages and disadvantages of this method.
\end{abstract}

Keywords: personal network, name generator, name interpreting questions, contact diary, network diary

DOI: $10.19055 / \mathrm{ams} .2011 .2 / 2 / 9$

Lektor: Dr. Bódi Ferenc, MTA Politikatudományi Intézet

\section{Introduction}

Theories of social networks are attached to theories of social structure, stratification and mobility. Social structure and stratification are determining contacts of persons. It is an important fact where a person stands in the society, which is his/her position.

We can talk about homogeneous contacts where the leading principle is similarity and heterogeneous contacts which underline connections of people in different status. 
The research of networks is an approach which has intensified for the last decades while similar proposal has been applied in the field of anthropology, social psychology and of course, sociology. Anthropology studies relationships of primitive societies. Radcliff-Brown, on the basis of his own research, established that every society has several kinds of structure depending on how we define them; geographical, gender, etc.

Besides, anthropologists focus on barter contacts, system of relatives' relations and the forming and working of normative regulation.

The methodology predecessor of the present network study is the most frequently cited sociometry which was developed by Moreno. As we know, Moreno wanted to measure the appearance of antipathy and sympathy in closed groups with multiple-choice questions. The weak point of sociometry is that it can only measure the given groups and organisations and contacts formed within them. However, we can declare that we cannot limit the person's network of contacts exclusively to the connections formed within the given groups or organizations. In all probability, contacts of a person will exceed the borders of a given group. In Hungary, Ferenc Mérei was the one who profoundly dealt with 'hidden networks of communities'. Nevertheless, school of sociometry still exists and it has been applied by researchers of micro-networks studies.

In addition to the above mentioned, the development of communication studies significantly influenced the network studies. It is worth mentioning the researches of R. Merton into 'local' and 'cosmopolitan' group roles in different communication circles. As for social psychology, the effects of researches into dyad and triad forms should also be emphasized.

An early research method of the 'small world' was first applied by S. Milgram at the end of 1960. Milgram asked the people involved in his research to send a package to a target person who was chosen in advance. People in Milgram's research could only send the package to those who were personal relations of them and about whom they supposed he/she knew the target person. The small world studies have shown that almost everybody, even the president of the United States or a pop star, can be reached in not more than six steps. This theory is called six-degrees of separation.

I suppose everybody has experienced the 'small world feeling' we should just think about travelling by train or dropping in a company and shortly afterwards we find ourselves talking vividly with the father of our ex-school mate or the child of our parents' neighbours. We should not forget about the popular community websites used world-wide.

When discussing the network science, the classics of sociology are needed to be referred to, first of all E. Durkheim, who in one of his most important books, The Suicide, pointed out that there is connection between religion and suicide. According to E. Durkheim, in the analysis researchers should take into account the contexts in which the person is and has been. Furthermore we need to mention G. Simmel and his theory about crosscutting social circles. In this theory, far ahead of 
his time, he deals with a social network approach. Last but not least the two-stair communication theory by P. Lazarsfeld must also be mentioned here.

\section{Methods to measure personal networks}

There are two main methods used in network studies, one of these is the situational name generator technique by Fischer and McCallister while the other one is the position generator by Lin and Dumin. With name generator we can measure peoples' strong ties while position generator is used to measure peoples' weak ties.

Nowadays collecting data with questionnaires is the most frequently used method to study connections and besides interviews they are often applied. Observation can be used as a method but it seems to works inefficiently.

In addition to cross section research researchers also apply longitudinal survey, which can measure changes of connection in time. To represent the network of connections they use graphs and socio matrixes while for the same reason more and more computer programmes come out like Ucinet or Pajek.

Indices of density, multiplexity or stratification are attached to Knoke and Kuklinski and R.S. Burt. Density index shows what proportion of an ego's theoretically possible connects are realized. Multiplexity of network describes several types of content appearing in connections among the actors of a given network. Stratification index shows the number of multiplex connections among the ego's contacts.

\section{Briefly about name generator}

As it was mentioned before, name generator serves to measure strong ties. According to M. Granovetter, strong ties mean members of families, relatives, friends, so mainly the homogeneous contacts. Weak ties have rather heterogeneous characteristic and they can be important from the viewpoint of a person's mobility and social integration. Granovetter's theory, re-developed by some researchers, is about the power of weak ties.

Name generator can be used by making a list with names in advance and then the egos are asked to describe his/her human contacts put on the list. On the other hand, this method can also be used by asking the egos to make their own name lists without restrictions.

In our opinion, the most frequent problem with this technique is that generally researchers delimit the number of names given by the egos, so we cannot study whole networks.

Ágnes Utasi also points out the weakness of this method since it can measure contacts which appear in certain situations made by researchers in advance. Usually they give three to seven situations to generate names therefore contacts which are not useful in those situations, although they can be useful in other types of 
situation, are missing. Furthermore, name generator does not measure contacts which are not active, though they can be very useful in certain cases.

\section{Briefly about position generator}

As we have already seen, researchers measure Granovetter weak ties by position generator. These ties can link the egos with people from other social status. Thus, weak ties have an important role in social integration, personal mobility and getting access to different resources. In applying position generator researchers list different occupations, professions and ask the egos to record if they have acquaintances among the given occupations.

\section{Whole networks or personal networks}

According to B.Wellman, 'personal network analysis views social network as one person's set of connections with others. Personal network analysis thus differs from the more common whole network analysis that views relationships among all network members in a bounded population ....Whole network analysts typically concentrate on uncovering the structure and composition of one big network, personal network analysts almost always study sample of many smaller personal networks.' (Wellman, 2007:111)

According to Wellman there are two issues with ego-reporting techniques: 1) 'egos may not accurately report on their relationships' (e.g. they overestimate their frequency of contacts with alters); 2) the characteristics of alters and ties are also imprecise. In my opinion, we may try to get around these problems with the well-edited diary method and we should work with interviewers. (Wellman, 2007)

\section{Size of personal network}

Different studies give different estimated size of personal network. J.Boissevain (1974) had observed inhabitants of Maltese Islands and stated that the ego dealt with 1750 alters during a year. 'Fu's contact diary study reported that egos contacted a mean of 227 alters in three months. The other extreme, time constraints, got the U.S.General Social Survey to ask the egos only about alters who helped them in important matters, yielding a mean of 2.1 alters. (Wellman, 2007:113)

\section{Difficulties in measuring personal networks}

According to Wellman, exclusively with surveys it is very difficult to reveal whole networks of egos, because 'asking about all of an ego's ties would be time consuming and unreliable (because of fatigue and forgetfulness).' That's why researchers usually give boundaries on which type of contacts they study, e.g. they focus only on strong ties.

Most of the studies into personal networks tend to map social support and social 
capital. 'In some cases, they also ask how much support there is, how often it is provided, or how reciprocally it is exchanged. Other studies obtain information on supportive exchanges more simply by providing a list of supportive resources and asking if the ego has access to each of them through their networks.' (Wellman, 2007:114). These methods apply techniques which are too factual and restricted, not revealing all the information.

Feld, Suitor and Hoegh's pointed out that composition and contents of networks often change in systematic ways therefore longitudinal data collection is advisable to use.

According to $\mathrm{Fu}$ 'although it has been innovative and illustrative to collect network data by various generators, all of these instruments procedure proxy measures of networks rather than actual networks.' (Fu, 2007:195)

Contact or network diary, as a new method, can be the solution to these problems and difficulties.

\section{What is contact diary?}

It is a method which was developed by $\mathrm{Fu}$ in Taiwan. 'Contact diaries contain self-recorded entries of contacts.' (Fu, 2007:196)

\section{And what is network diary?}

It is a method that is being developed by Angelusz and Huszti in Hungary. Network diaries study an ego's contacts on daily basis in a given time interval.

\section{Earlier researches using diaries}

It was Gurewitch who used the contact diary as a pioneer in the USA in 1961. There were eighteen people who served as egos and who recoded each day for hundred days the socio-demographic characteristics of those acquaintances with whom he or she had contact. 'The rich information from these diaries revealed the social structure of acquaintanceship networks.' Another research, where contact diary was used, was Lonkila's study in Russia and Finland in 1999. They instructed seventy-eight schoolteachers to record 'nonroutine' contacts with their acquaintances for more than two weeks (fifteen days). The research was repeated few years later with fewer teachers and shorter periods. Despite the changes, diaries proved to be very informative. With this method researchers revealed the teachers' network and interpreted the process of network formation.

The above mentioned studies and Fu's researches of his own have demonstrated that contact diary can help collect empirical and actual data on interpersonal contacts and it will become an ultimate database of comprehensive personal network. $(\mathrm{Fu}, 2007)$ 


\section{Network diary}

In the next part a brief description will be given on network diary as well as some of our results.

At an early stage of our study, we realized the necessity of a survey method which could measure personal network more efficiently and which can give more valid data than earlier used ones.

Our original idea was to examine the working power of weak ties in a particular agent, namely poor people who lived in a special housing situation that prevented them from becoming homeless. We wanted to know how weak ties served the social reintegration of this group. We considered it important to know who personalized the weak ties and how these people's personal network worked. We wondered if there were 'bridges' at all and who could serve as a link between people from different social status.

That was the turning point when the idea of our new method was born. Thus, network diary is a method that studies an ego's networks.

At the beginning a school exercise-book was applied as a diary. On the inner cover of the exercise-book there was a short instruction in which we asked the egos to report on people with whom they met during certain time of the day. Since we had no the intention to edit diaries in advance, we divided days of the week into six parts like Monday early morning, in the morning, at noon, in the afternoon, in the evening and at night. With this technique we gave the egos a free hand to find the best way of keeping the diary. There were some egos who wrote everything about their days as in a real diary, but there were respondents who wrote only the necessary information.

We also asked egos to describe alters according to the following questions: name, age, current residence, occupation, the frequency of meet, duration of acquaintanceship, evaluation of his/her relationship with alter with a 5-degree scale and finally where the ego met the alter. In the diary there was a short questionnaire about the ego's age, sex, level of education, occupation, family status, income in the last six months, number of good friends, number of relatives living close to the egos, frequency of meeting relatives, starting date of current residence, place of birth. The egos were expected to keep diary for a week.

It was an important factor how good and applicable the diary was. According to $\mathrm{Fu}$, 'the key success lies in maintaining a balanced focus on what researchers want and how informants record their daily contacts. To collect detailed data, researchers should aim to design a diary log that covers wide-ranging topics'. (Fu, 2007:198)

We agree with $\mathrm{Fu}$ with regard to first experience network diaries. We set out from our original concept not to restrict respondents with viewpoints they should keep in mind when writing about alters into the diary. There was only one fixed point to be followed for the egos, time of days divided into parts. It proved useful 
because respondents could link events to any six parts of the day in their memories. Besides, experiences showed the more orientation was given to motivate them the more detailed was the evocation.

On the ground of our experiences the contemporary version of network diary, that is used at the moment in a research in my hometown, Nyíregyháza, is built as follows:

- There are some simply sentences about social contacts.

- It contains suggestion on keeping diary; when and how to write diary, which is the most practical and convenient method to write it, what type of contacts they should write about, etc.

- It contains four main steps to keep a diary:

1. 'Please, think over your day carefully and remember those you have met and talked to for some minutes today from early morning to late at night. Give monograms or nicknames to those you spoke to for some minutes besides say hello.'

2. 'Please, think it over now whether you have forgotten about someone you met and speak to for some minutes today. Record those you have forgotten earlier.'

3. 'Please, try to evocate if you have been involved talking in a bigger group today. Record them, too'

4. 'Now, you should record everybody in your diary according to the given viewpoints. Please, try to collect and write as much information as you can about the persons in your diary. If you are not sure of something, e.g. you do not know exactly his/her age, please, try to estimate and sign it with a small star.'

- The diary contains seven days in two pages where the egos can make notes and describe their contacts. Besides, there is an extra page for alters the egos have not met during the examined week but are important for them.

In the following part of our study we introduce the name interpreting questions:

- monograms or nicknames of alters

- $\operatorname{sex}$

- age

- level of education (1.primary school, 2.secondary school, 3.college/university)

- occupation 
- current residence

- duration of acquaintanceship (1. from that moment, 2. for some days, 3. for weeks, 4. for months, 5. for years)

- relationship to you (1. spouse, 2. parent, 3. child, 4. brother/sister, 5 . other relatives, 6. former neighbour, 7. current neighbour, 8. former classmate, 9. current classmate, 10. former teacher, 11. current teacher, 12. former colleague, 13. current colleague, 14. close friend, 15. other)

- Have you been at his/her home?

- frequency of talking (1. daily, 2. weekly, 3. in several occasions per week, 4. in several occasions per months, 5 . monthly, 6. more rarely than monthly)

- place of meeting (1. your residence, 2. work place/school, 3. business place (bank, post, etc.), 4. public place (street, restaurant, coffee bar, pub, etc.), 5. residence of the contacted person, 6. work place of the contacted person, 7. other)

- form of talking (1. face to face, 2. phone, 3. chat/skype/messenger/email/etc)

- Who initiated contact? (1. you, 2. he/she, 3. somebody else, 4. nobody, you met by chance)

- How many people were there besides you?

- How well do you like contacted person (from 1 to 5 , where 1 means dislike very much, 5 means like very much)

- Do you talk about things which are important to you with this person?

\section{Sampling}

The above mentioned researchers who applied contact diary selected the sample according to occupational status. Others examined specific groups like college students, university employees, schoolteachers, mothers with preschool children, etc. 'It is not unusual for researchers to recruit their own network members in studies.' (Fu, 2007:203)

At the first stages of our study we applied the same 'sampling', we tested network diary with my friends.

Thus, number of informants is limited and low, researchers try to use samples with reasonable distribution based on sex, age, region and occupation. (Fu, 2007) 


\section{Own sample}

We also aimed at selecting a good sample in the current research. The base population was served by Nyíregyháza Household Panel with 1,200 inhabitants. We made a sub-sample with 100 people and this sub-sample was a representative to sex and age of the main sample. Because of bad response rate we chose another sub-sample with 100 people to remain representative sample.

\section{The 'mystery' of diary keeping}

\section{Duration of contact to record into diary}

It is important to give clear guidelines to informants as to what type of contacts they should record into the diary. 'Most diary studies have limited the types of interactions and target persons as the candidates for diary entries.' E.g. they were asked to write only acquaintances. (Fu, 2007:204)

In our research we limited the contacts to record to meetings lasted more than 5 minutes and we also added that informants should write about important contacts, regardless the time limit. In our opinion some of these short contacts may be more important than longer contacts.

At this point we need to mention the interpretation problem of strong and weak ties: it is not sure if a tie defined as strong tie is really strong and gives suitable resources. To the contrary, we can get more useful information and resources from ties defined as weak but would prove important and significant in our life. According to $\mathrm{Fu}$, and I agree with him again, 'recording all one-on-one contacts with all kinds of persons, the informants provide rich information about their personal network in daily life.' (Fu, 2007:204)

\section{When is it practical to record events into the diary?}

It is a question of 'war' with our memories when we should, need to record daily contacts in order to give as much information as we can. According to Fu, the egos can choose from three main strategies: 1.) 'interval-contingent (to record contacts at regularly scheduled intervals)'; 2.) 'signal-contingent (to record whenever one receives a signal, such as a beeper signal or a message from researchers)'; 3.) 'event-contingent (to record whenever an event occurs).' (Fu, 2007:204)

We can easily realize the latest one is 'minimizing in bias recall' but if respondents take their time 'to record each contact immediately after it ends, it tends to interrupt the natural flow of social interactions, thus modifying their future contacts'. (Fu, 2007:204) So, there is no magic formula concerning when egos need to record events into the diaries because it depends on the person.

The interval-contingent seems more practical. 'Some studies have asked informants to record their contacts at the end of each day, when these contacts were still fresh in their minds, whereas others have used shorter intervals e.g. every 6 
hours or three times a day to allow better supervision.' (Fu, 2007:205)

In our research we asked respondents, if it was possible to record their contacts every night, before going to bed. Respondents, who tested the diary, confessed it was hard to record events after they missed a day.

Other researchers advised respondents to make short notes about their contacts during the day making it possible to remember every contact when it came to record them. In our pre-research the most informative diaries proved to be the ones where note-taking was applied during the day. They were only short notes and did not interrupt the natural flow of interactions but made it possible to remember every detail when registering contacts into the diary.

\section{For how long should respondents record contacts into the diary?}

It is necessary to ask this question because diary keeping is quite time consuming and may be boring what's more it is a big favour from the respondents. According to $\mathrm{Fu}$, 'The optimal duration of diary keeping is a trade-off between costs and benefits'. (Fu, 2007:205) We can ask informants 'to keep diaries as long as possible to obtain an exhaustive list of network members'. (Fu, 2007:205) Or we can ask them to write a shorter period. It may be more 'friendly', but we get less information about personal networks. 'The pre-existing contact diaries lasted from 1 week to 100 days, and a 'typical' diary usually took 1-2 weeks to finish.' (Fu, 2007:205)

In our study we gave a one-week interval and according to our pre-test it was a well-chosen period for respondents, as well. The period being not too long, respondents did not refuse diary keeping while at the same time, it was sufficient to get a good picture of personal contacts. In our opinion it would be worth repeating diary keeping after a certain time with the same respondents. Thus, we would have two separate one-week diaries, which would not overload the respondents, and we would also have a better picture of personal network in general.

\section{What can researchers do to motivate respondents?}

$\mathrm{Fu}$ mentioned tangible and intangible resources to motivate respondents. In Fu's research respondents got 100 dollars per month, because they spent 20-40 minutes per day keeping diary. But as Fu recognized 'bonus payment raises a concern that some informants might make up false entries to boost the amount of compensation'. (Fu, 2007:206-207) That's why researchers usually 'checked the entries for logic and consistency and verified whether the content of entries matched the informant's work, family and lifestyle'. (Fu, 2007:207)

It would be an efficient method to apply fieldwork supervisors or interviewers which may increase the validity of research since interviewers can give useful help to respondents with diary keeping.

We also asked interviewers to help with data collection. Their main task was 
to give information to respondents about network diary and the research. We asked interviewers to visit every respondent at least two times a week. On the first meeting, they filled in a seven-situation name generator with name interpreting questions together with the informant. Then they filled in the network diary regarding the given day together with the informant again. The main goal of this first meeting was to give help to the respondents with diary keeping so that to be able to that alone for a week. If it was necessary the interviewer went to see the respondents again in the middle of the week. On the last meeting interviewers checked the network diaries with the respondents and if it was necessary or possible they filled in the empty places.

\section{Results of our pre-research}

In the following part of this study I would like to give a short summary of the results of our pre-research. During this research we wanted to test how the first version of our diary worked. There were 38 informants who filled in the network diary in 2008 and the informative results are the following:

- The size of general network was 30 , so informants met 30 different people during a week,

- The maximum size of network was 64 people.

- The rate of relatives was $26 \%$.

- Almost half of the informants (49\%) did not record any friends in their personal network during a week.

- Among those who met friends during the examined week, the average number of friends was 1.7.

- The greatest number of friends of an ego was 9 .

- The greatest number of friends were recorded by people above 30 years of ages,

- The rate of acquaintances from workplaces was $23 \%$, which significantly does not differ from rate of relatives.

- Informants seem to keep contact mostly with their relatives and acquaintances from workplaces.

- We compared the rate of relatives with that of acquaintances from work places and that of neighbours. In general, there was one group (relatives, acquaintances, neighbours) which was the most important for an ego. Those who had more frequent contacts with their relatives, recorded less acquaintances from 
workplaces and neighbours and if somebody recorded more acquaintances from workplaces, they had less contacts with relative during the examined week.

- According to sex, homogeneous contacts were typical. Men recorded more contacts with men and women recorded more contacts among their own sex.

- At the age of 35 it was typical that informants kept contact with younger people while above 35 , the situation changed - more frequently their own age group and an elder age group were recorded in the personal network.

Thus, network diary can be a new method to measure personal network which can increase validity of personal network researches. We can get more contacts with network diary than with earlier methods. In giving information it is served like a real diary. On one hand, we can get to know a wider range of contacts than with name generator while on the other hand, these contacts will not be anonymous like the ones we get with position generator.

It is also important to mention that network diary can make the wider fields of contacts visible which exist between strong and weak ties which stayed in the shadow in the earlier studies. Besides, we emphasize that contacts from workplaces which were not measured by name generator, but we could see how important role acquaintances from place of work have among informants.

Further results of our pre-tests is that regarding the personal network we could get more information; network dairy gives a week cross-section about how an ego's networks are working; with network diary vertical and horizontal channel of communication may be recognized; researchers can use network diary in their own research fields like differences between contacts of men and women; connection of informal economy and social networks; role of weak and strong ties in creating places of work.

We also need to mention the limitations of diary. We do think that diary keeping in a research is quite intensive and overload both researchers and informants. The other risk factor may be a high attrition among informants. It is still a question to be answered whether network diary can work with a bigger sample.

\section{Conclusion}

During data collection it is an important factor for a sociologist to choose the best method which will fit into the theme of our research since we need to choose a good measuring method to get valid data.

Besides, we have to take the contexts of data collection into consideration. The most positive consequence of network studies is that they can dissolve the dilemma of examining isolated persons, because they study embedded persons with their contacts and persons are not cut out from the society. Thus, contextual analysis becomes possible. 
A further advantage of network studies is that conflicts between micro and macro analyses can be cancelled, due to the middle-level analysis.

\section{References}

- Albert Fruzsina-Dávid Beáta (2006): A kapcsolati tóke dimenziói etnikai metszetben. In: Társadalmi Riport, Tárki, Bp. Albert Fruzsina-Dávid Beáta (2007): Embert barátjáról. A barátság szociológiája. Századvég Kiadó, Bp.

- Angelusz Róbert-Tardos Róbert (1998): A kapcsolathálózati erőforrások átrendezôdésének tendenciái a kilencvenes években. In: Társadalmi Riport, Tárki, Bp.

- Angelusz Róbert-Tardos Róbert (szerk.) 1991.: Társadalmak rejtett hálózata. Magyar Közvéleménykutató Intézet, Bp.

- Fu, Yang-Chih: Contact Diaries: Building Archives of Actual and Comprehensive Personal Networks. In: Field Methods, Vol.19, No. 2, May 2007 194-217.

- Kürtösi Zsófia: A társadalmi kapcsolatháló-elemzés www.socialnetwork.hu

- Tardos Róbert: Kapcsolathálózati megközelítés: Új paradigma? www.socialnetwork.hu

- Utasi Ágnes (2002): A bizalom hálója. Új Mandátum Könyvkiadó, Bp.

- Wellman, Barry (2007): Challenges in Collecting Personal Network Data: The Nature if Personal Network Analysis. In: Field Methods, Vol.19, No. 2, May 2007 111-115.

\section{Éva Huszti}

University of Debrecen, Faculty of Health Nyíregyháza, 4400, Sóstói út 2-4. 